\title{
Influence of three plant species with different morphologies on water runoff and soil loss in a dry-warm river valley, SW China
}

\author{
Xian-Li Xu ${ }^{\text {a }}$, Ke-Ming Ma ${ }^{\text {a,* }}$, Bo-Jie Fu ${ }^{a}$, Cheng-Jun Song ${ }^{a}$, Wen Liu ${ }^{b}$ \\ a State Key Laboratory of Urban and Regional Ecology, Research Center for Eco-Environmental Sciences, Chinese Academy of Sciences, 18 Shuangqing Road, \\ Haidian District, Beijing 100085, PR China \\ ${ }^{\mathrm{b}}$ School of Information Science and Technology, Beijing Institute of Technology, Beijing 100081, PR China
}

\section{A R T I C L E I N F O}

\section{Article history:}

Received 30 November 2007

Received in revised form 6 May 2008

Accepted 9 May 2008

\section{Keywords:}

Plant morphology

Water runoff and soil loss

Soil erosion

Arid environments

Vegetation restoration

\begin{abstract}
A B S T R A C T
Understanding of the effects of isolated plants with different morphologies on water runoff and soil loss is important for vegetation restoration in arid environments. We selected three representative species (Artemisia gmelinii; Ajania potaninii; Pulicaria chrysantha) of the dry-warm river valley of the upper reach of Minjiang River, SW China to examine these effects. Twenty-five runoff events were recorded using runoff plots at micro scale $(<40 \mathrm{~cm} \times 40 \mathrm{~cm})$ on a south facing slope from July through October 2006 . $A$. potaninii had sparse canopy, the smallest leaf area $\left(0.49 \pm 0.25 \mathrm{~cm}^{2}\right)$ and specific leaf area $\left(67.8 \pm 16.5 \mathrm{~cm}^{2} /\right.$ $\mathrm{g})$, and the highest leaf relative water content $(27.1 \pm 4.4 \%)$. It is the most resistant to drought stress. $A$. gmelinii was the shortest, and had relatively small leaf area $\left(0.55 \pm 0.50 \mathrm{~cm}^{2}\right)$ and the densest canopy. $P$. chrysantha had the greatest leaf area $\left(1.41 \pm 0.49 \mathrm{~cm}^{2}\right)$ and most extended canopy $\left(4450 \pm 1646 \mathrm{~cm}^{2}\right)$. Dead branches and leaves of $A$. gmelinii and P. chrysantha commonly fall and collect on the soil surface. Thus they had greater improvements on soil porosity and soil water content, and higher effectiveness in controlling soil loss. However, A. gmelinii had more stable effectiveness in controlling runoff as compared with $P$. chrysantha. The characteristics such as relatively small leaf area but low height and dense canopy might be one criterion for selecting species to improve soil properties and controlling runoff and soil loss. Differences in soil environments, and runoff and soil loss production capacity for micro-surfaces regulates water and materials redistribution, which emphasizes the importance in designing vegetation restoration pattern.
\end{abstract}

(c) 2008 Elsevier B.V. All rights reserved.

\section{Introduction}

Vegetation and water erosion processes can strongly interact in landscapes. One particularly important interaction between these processes in patchy semiarid lands is how vegetation patches serve to control water erosion and then how this retained water runoff and soil material increase vegetation growth that, in turn, provides feedbacks to the system (Ludwig et al., 2005). These interactions could also lead to microtopography change that could further affect water runoff and soil loss processes (Bergkamp, 1998). Many studies have proved increasing vegetation cover is an important measure to control water erosion, and to improve soil environments (Hidalgo et al., 1997; Cerda, 1998; Martinez-Mena et al., 1999; Sanchez et al., 2002; Durán Zuazo, 2004; Xu et al., 2006b). However, few were conducted at individual plant scale (De Baets et al., 2007), on which we could relate such effects to plant

\footnotetext{
* Corresponding author. Tel.: +86 10 62849104; fax: +86 1062849104

E-mail addresses: xuxianliww@gmail.com (X.-L. Xu), mkm@rcees.ac.cn (K.-M. Ma).
}

morphology and thereby provide necessary information to select suitable plant species in terms of plant morphology for vegetation restoration in arid and semiarid environments. Moreover, the existing studies at individual scale were mainly concentrated in Mediterranean landscapes (Bochet et al., 1998, 2006; Casermeiro et al., 2004). In these studies of individual plant scale, small runoff plots $\left(<1 \mathrm{~m}^{2}\right)$ was often used to monitor runoff and soil loss. These plots are very efficient at representing the hydrological behaviors of different surfaces to allow comparisons between them (BoixFayos et al., 2008).

The dry-warm river valley of upper reach of Minjiang River in mountainous area, SW China, experienced much disturbance (Yan et al., 2006), which caused sparse vegetation distributing in a mosaic of vegetated patches or isolated plants and bare surfaces, and therefore resulted in severe soil degradation and soil loss. Estimated by Lu et al. (2003), sediment delivery from this area is between 1000 and $5000 \mathrm{t} \mathrm{km}^{-2}$ year $^{-1}$. This area has become the key region for eco-environmental rebuilding under the National Eco-environmental Renovating Scheme of China (Li et al., 2006a). Many restoration studies have been conducted in this area (Li et al., $2005,2006 b)$, however, most of which mainly focused on the 
response and adaptation of certain plant species to environmental stresses, and scarcely related vegetation to water runoff and soil loss. Especially, few studies paid attention to the effects of plant morphology on water runoff and soil loss (Xu et al., 2006a).

Based on the analysis above, this paper aimed to (i) examine the differences in some plant characteristics of three representative species of this arid environments as well as relate these characteristics to water runoff and soil loss, and some soil properties at individual scale, (ii) investigate the relationships between slope gradient and water runoff and soil loss at micro scale.

\section{Site descriptions}

The study site is located at Maoxian county (31 $37^{\prime} 20^{\prime \prime}$ $31^{\circ} 44^{\prime} 53^{\prime \prime} \mathrm{N}, 103^{\circ} 54^{\prime} 04^{\prime \prime}-103^{\circ} 56^{\prime} 52^{\prime \prime} \mathrm{E}$ ), which belongs to Aba prefecture of Sichuan Province in southwest China (Fig. 1). This area is part of the dry-warm river valley of upper reach of Minjiang River, which is one of the four principal tributaries of the Yangtze River. Mountain peaks 1500-3500 m above the deep river valley are the prominent local topographical features of the area. The mean annual temperature is $11.2{ }^{\circ} \mathrm{C}$, and mean annual precipitation is $494 \mathrm{~mm}$ with about $83 \%$ of this occurring throughout April-October (wet season). Two peak rainfall occurrences are during the wet season with one from AprilJune, and the other from August-September. Mean annual evaporation is $1332 \mathrm{~mm}$. The aridity index (the ratio of potential maximum evaporation to rainfall) for this area is within 1.53.49, which is typical of semiarid environments ( $\mathrm{Chu}$ and $\mathrm{Li}$,
1989). Brown soil is the predominant soil type-shallow depth $(10-30 \mathrm{~cm})$ and coarse texture (sand, $28.7 \%$; silt, $68.7 \%$; clay, $2.6 \%$, percent by volume). Grassland and shrubland cover above $48 \%$ and $40 \%$ of the area, respectively. The vegetation mainly comprise drought-tolerant species, e.g., Sophora davidii, Cotinus coggygria, Bauhinia faberi var. microphylla, Jasminum nudiflorum, Ostrypsis davidiana, Cotoneaster spp., Convulus tragacanthoides, and Ajania potaninii are the predominant shrub species; Artemisia gmelinii and Pulicaria chrysantha are the predominant herbaceous species. In this study, we selected three species (A. potaninii, $A$. gmelinii and $P$. chrysantha) for the following reasons: (1) the three species are common in this area; (2) the three species include both shrub and herbaceous species, and (3) they each have unique morphologies and grow in the same area, which facilitates sampling. A. potaninii is a small perennial shrub widely distributed throughout the entire river valley. Its stems and branches grow separately and erectly, thus creating a sparse canopy. Its leaves are relatively thin, small, and sclerophyllous (Fig. 2c); A. gmelinii is a perennial tussock, which is widely distributed in semiarid ecosystems associated with the river valley. It is relatively short with a dense, umbrella-shaped canopy, with branches and leaves that often reach the ground (Fig. 2b). Dead branches and leaves commonly fall and collect on the soil surface; $P$. chrysantha is a perennial grass that is widely distributed in the semiarid ecosystems of the river valley. It is highly branched, and the branches grow outwards so that the canopy resembles an inverse cone. It has relatively large leaves that resemble feathers (Fig. 2d). Dead branches and leaves commonly fall and collect on the soil surface. Note that Latin names are used for all plant species in this study.

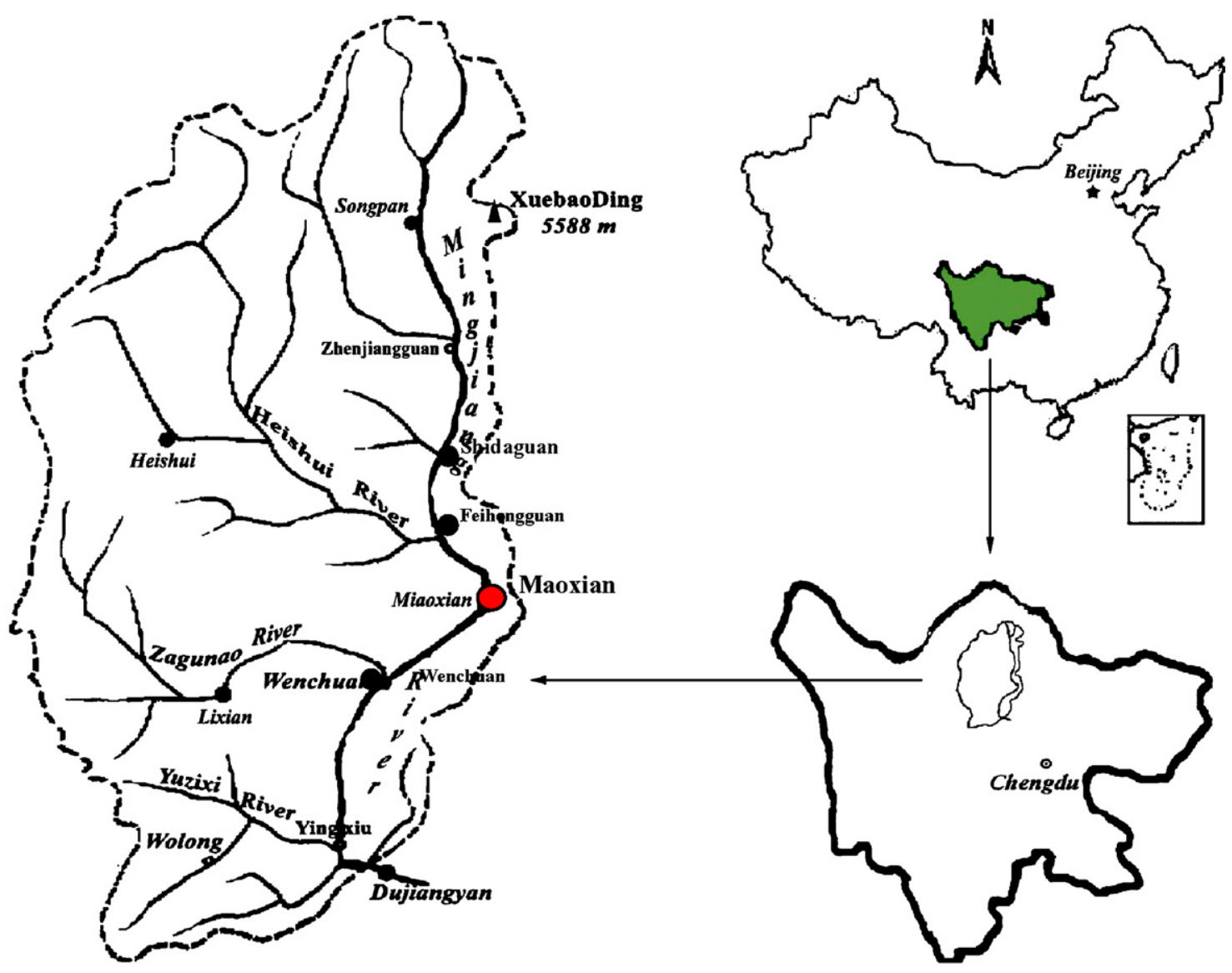

Fig. 1. The location of the study site. 

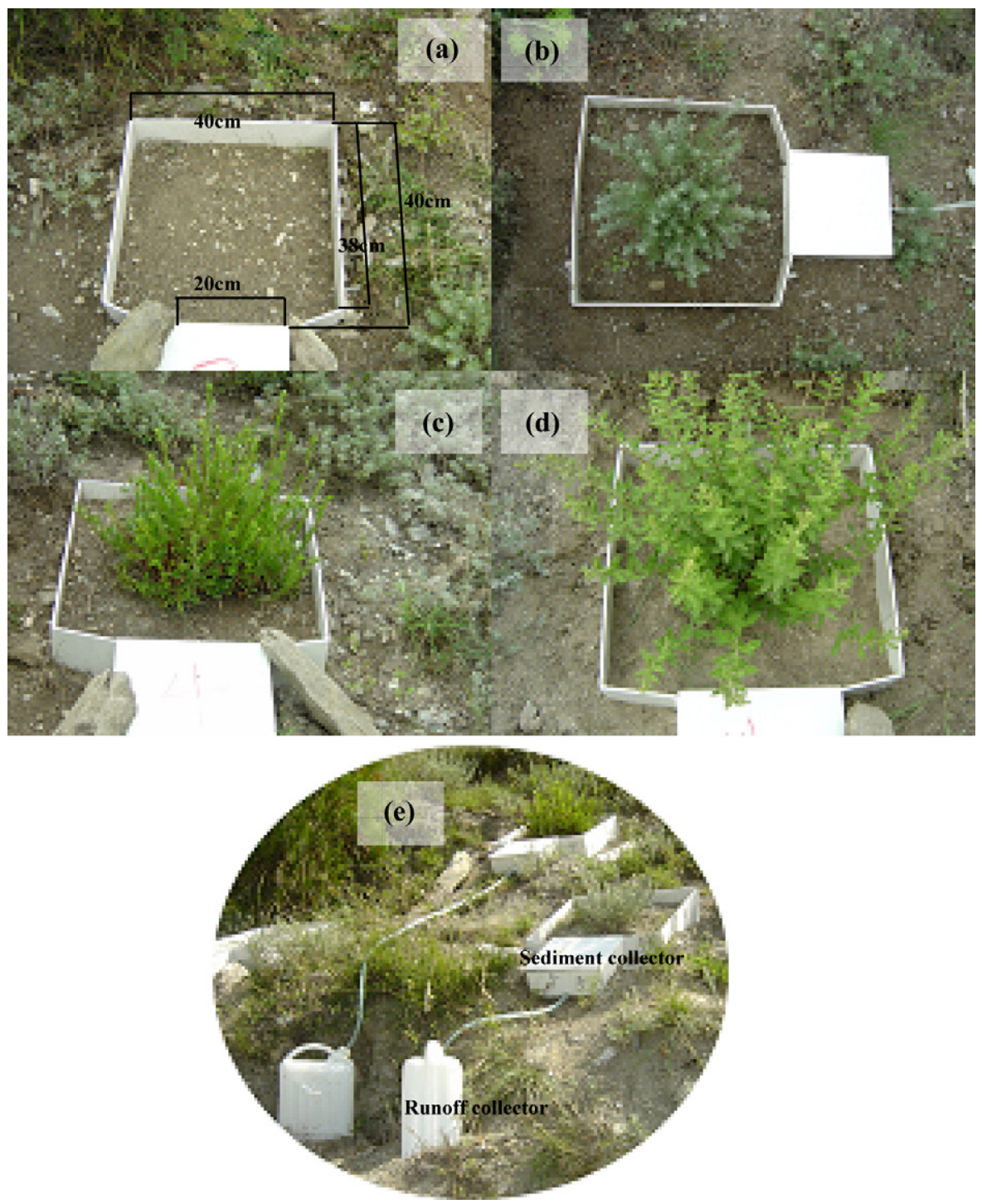

Fig. 2. Runoff plots for (a) Control (bare surface); (b) A. gmelinii; (c) A. potaninii; (d) P. chrysantha; (e) overview of the runoff collection system.

\section{Methods}

\subsection{Runoff and soil loss measurements}

We built 18 runoff plots on a south-facing slope at the end of June 2006. There are 6 for bare ground (Control treatment, Fig. 2a) and 4 for each plant species. The observation duration spanned 4 months from July through October 2006, which can catch the second rainfall peaks (August and September). Bare plots with slope gradient from 18 to $44^{\circ}$ are used to explore the relation of slope gradient to runoff depth and soil loss. The plots of the three plant species with different plant cover and similar slope are used to seek the relation of cover to runoff depth and soil loss. Runoff volume was measured after each rainfall event, and then transformed to runoff depth by dividing the volume by the projected plot area. Sediment was taken into the laboratory, dried at $105{ }^{\circ} \mathrm{C}$ and weighed $\left(W_{\text {sed }}\right)$. To calculate the soil loss, we divided $W_{\text {sed }}$ by the projected area of the plot. The plant characteristics including canopy length (along slope), canopy width (cross slope), plant height and cover were recorded monthly from July through October 2006, and averaged. Each plot was enclosed with PVC material $(<40 \mathrm{~cm} \times 40 \mathrm{~cm}$, see Table 1$)$, and inserted into soil matrix at about $5-\mathrm{cm}$ in depth (Fig. 2).

\subsection{Plant characteristics and leaf traits measurements}

To avoid disturbance of cutting off branches on runoff plots, we selected the plants beside instead of in the plots to measure their morphological characteristics and leaf traits in August 2006, the best growing season. After measuring the morphological characteristics of all plants (20 plants per species), we cut off 5-10 branches per plant (10 plants per species), and put them into plastic bags for measurements of leaf traits in the laboratory.

(1) Plant characteristics, including canopy length ( $L$, along slope), width ( $W$, across slope), canopy area $=L \times W$, plant height.

(2) Leaf traits, including leaf area, relative leaf water content, specific leaf area. Relatively intact and representative leaves were selected from branches to weigh, fresh weight (W1). After dipping in water for $24 \mathrm{~h}$ we weighed them (W2) again, and then dried them (at $70^{\circ} \mathrm{C}$ ) in oven to constant weight (W3). Leaves were put on a piece of filter paper with specified size as a 
Table 1

Conditions of runoff plots

\begin{tabular}{|c|c|c|c|c|c|c|c|}
\hline \multirow[t]{2}{*}{ Treatments } & \multirow[t]{2}{*}{ Code } & \multirow[t]{2}{*}{ Slope $\left({ }^{\circ}\right)$} & \multirow[t]{2}{*}{ Projected area $\left(\mathrm{m}^{2}\right)$} & \multicolumn{2}{|l|}{ Canopy $(\mathrm{cm})$} & \multirow[t]{2}{*}{ Plant height $(\mathrm{cm})$} & \multirow[t]{2}{*}{ Canopy cover (\%) } \\
\hline & & & & Length (along slope) & Width (across slope) & & \\
\hline \multirow[t]{6}{*}{ Control } & 1 & 19.4 & 0.149 & & & & \\
\hline & 2 & 25.5 & 0.143 & & & & \\
\hline & 3 & 27.5 & 0.140 & & & & \\
\hline & 4 & 36.8 & 0.127 & & & & \\
\hline & 5 & 18.3 & 0.150 & & & & \\
\hline & 6 & 43.5 & 0.110 & & & & \\
\hline \multirow[t]{4}{*}{ A. gmelinii } & 1 & 28.3 & 0.139 & 40 & 50 & 26 & 65 \\
\hline & 2 & 28.5 & 0.139 & 40 & 50 & 35 & 79 \\
\hline & 3 & 30.0 & 0.137 & 20 & 28 & 20 & 23 \\
\hline & 4 & 30.5 & 0.136 & 42 & 42 & 27 & 56 \\
\hline \multirow[t]{4}{*}{ A. potaninii } & 1 & 25.0 & 0.143 & 36 & 45 & 43 & 63 \\
\hline & 2 & 27.5 & 0.140 & 35 & 35 & 29 & 34 \\
\hline & 3 & 28.0 & 0.140 & 48 & 36 & 25 & 55 \\
\hline & 4 & 28.0 & 0.140 & 40 & 50 & 42 & 66 \\
\hline \multirow[t]{4}{*}{ P. chrysantha } & 1 & 24.0 & 0.144 & 46 & 37 & 39 & 55 \\
\hline & 2 & 25.0 & 0.143 & 40 & 43 & 33 & 63 \\
\hline & 3 & 26.4 & 0.142 & 40 & 35 & 39 & 30 \\
\hline & 4 & 27.3 & 0.140 & 34 & 37 & 31 & 75 \\
\hline
\end{tabular}

reference, and then they were taken pictures using digital camera and digitized within ArcviewGIS software. The leaf area was digitized and measured by ArcviewGIS software. Leaf relative water content $=(W 1-W 3) /(W 2-W 3) \times 100 \%$, and specific leaf area $=$ leaf area $/ W 3$.

\subsection{Soil properties}

To compare soil properties among the four treatments (Control, A. gmelinii, A. potaninii, and $P$. chrysantha), we sampled and analyzed soil properties for each treatment in August 2006, which is typically the best growing season. In order to avoid disturbance in runoff plots and to simultaneously test soil similar to those runoff plots, we selected plant-covered and bare surfaces on the same slope, but not within the bounds of these plots. Topographic conditions of sample sites to that in runoff plots, and the selected plants were average-sized for each species. In total, 7 A. gmelinii, 6 A. potaninii, 5 P. chrysantha, and 4 Control (bare ground) sites were selected. The soil with metal core $\left(100 \mathrm{~cm}^{3}\right)$ was hot-dried at the temperature of $105{ }^{\circ} \mathrm{C}$ until the weight had no change, then we calculated the bulk density, soil water content and total porosity (similar to the study by Li and Shao, 2006). In addition, to avoid intensive destructions of digging soil at certain points, we reselected other points to take another soil samples. One metal core for each point ( 5 points per treatment) was employed to measure infiltration capacity (Ks). One empty metal core was joined to the other with full soil by adhesive tape (Institute of Soil Science, CAS, 1978). We firstly fully fill the empty core with water, and then fully refill it again with water at 2 min interval until $60 \mathrm{~min}$. According to the poured water, we calculated infiltration rate, Ks ( $\mathrm{mm} / \mathrm{min})$. From the changing curve of Ks over time, we found the time point from which the Ks begin to have a steady state. Then we averaged all the Ks values after that time point as the steady Ks.

\subsection{Statistical analysis}

Any individual plant, whether large or small, reflects the morphology of certain species. Only if we consider different individual plants with canopy covers ranging from low to high, can we fully examine the effects of certain species. Thus the observed values of Control-1 and 2, of A. gmelinii-1, -3 and -4 , of $A$. potaninii$1,-2$ and -3 , and of $P$. chrysantha-1, -2 and -3 were averaged to represent respective treatments (species). All the selected plots have similar slope gradient with each other, and each species includes individuals from both low and high canopy cover situations. To more clearly discern the effects of certain species, we also compared the equations established between runoff (soil loss) and canopy cover among the three species.

One-way analysis of variance (ANOVA) with Tukey method was employed to compare the difference for different variables between different treatments in SPSS software (at 0.05 level). Regression analysis was also conducted in SPSS software (at 0.05 level). Note that in the course of regression analysis, we added the bare plot, Control-2 with most closely slope degree to the plots for plants, to every plant treatment set as 0 in plant canopy length and width, and plant cover. In total, there were 25 records of runoff depth value; only 23 records of soil loss value because of misoperation.

\section{Results}

\subsection{Plant characteristics and soil properties for different treatments}

P. chrysantha had the greatest canopy length, canopy width, canopy size, and plant height among the three plant species, while A. gmelinii had the least ones (Table 2). The three species had significantly statistical difference in leaf traits (Table 2). The leaf area of $P$. chrysantha was 1.87 and 1.56 times greater than $A$. gmelinii and $A$. potaninii. The specific leaf area of $A$. potaninii was the smallest $\left(67.8 \pm 16.5 \mathrm{~cm}^{2} / \mathrm{g}\right.$, mean \pm standard deviation), whereas it was the greatest for $P$. chrysantha $\left(142.4 \pm 20.0 \mathrm{~cm}^{2} / \mathrm{g}\right)$. For relative leaf water content, $A$. potaninii had the greatest value $(27.1 \pm 4.4 \%)$, and was significantly greater $(p<0.001)$ than $P$. chrysantha $(21.5 \pm 2.7 \%)$ and $A$. gmelinii (18.6 $\pm 1.9 \%)$.

For the four treatments, they had statistically significant difference in soil bulk density and total porosity $(p<0.01)$. The bulk density was highest for Control and $A$. potaninii, while it was lowest for A. gmelinii. Correspondingly, the total porosity was just opposite to the bulk density (Table 3 ). The four treatments had marginally significantly different soil water content $(p=0.058)$, and the order was $P$. chrysantha $>A$. gmelinii $>A$. 
Table 2

Mean \pm standard deviation (sample number) of plant characteristics and leaf traits

\begin{tabular}{|c|c|c|c|c|c|c|c|}
\hline \multirow[t]{2}{*}{ Treatments } & \multicolumn{3}{|l|}{ Canopy } & \multirow[t]{2}{*}{ Plant height $(\mathrm{cm})$} & \multicolumn{3}{|l|}{ Leaf } \\
\hline & Length $(L)(\mathrm{cm})$ & Width $(W)(\mathrm{cm})$ & Area $\left(\mathrm{cm}^{2}\right)$ & & Area $\left(\mathrm{cm}^{2}\right)$ & $\begin{array}{l}\text { Specific leaf } \\
\text { area }\left(\mathrm{cm}^{2} / \mathrm{g}\right)\end{array}$ & $\begin{array}{l}\text { Relative water } \\
\text { content }(\%)\end{array}$ \\
\hline A. gmelinii & $50 \pm 8 b(20)$ & $47 \pm 8 b(20)$ & $2395 \pm 680 b(20)$ & $29 \pm 5 c(20)$ & $0.55 \pm 0.50 \mathrm{~b}(109)$ & $85.0 \pm 19.1 b(10)$ & $18.6 \pm 1.9 \mathrm{~b}(10)$ \\
\hline A. potaninii & $53 \pm 11 \mathrm{ab}(20)$ & $53 \pm 9 a b(20)$ & $2868 \pm 976 \mathrm{ab}(20)$ & $37 \pm 7 b(20)$ & $0.49 \pm 0.25 b(90)$ & $67.8 \pm 16.5 b(10)$ & $27.1 \pm 4.4 \mathrm{a}(10)$ \\
\hline P. chrysantha & $65 \pm 15 a(20)$ & $65 \pm 15 a(20)$ & $4450 \pm 1646 a(20)$ & $43 \pm 9 a(20)$ & $1.41 \pm 0.49 a(69)$ & $142.4 \pm 20.0 \mathrm{a}(10)$ & $21.6 \pm 2.8 b(10)$ \\
\hline$F$ & 6.993 & 9.102 & 7.012 & 20.714 & 113.53 & 44.081 & 17.851 \\
\hline$p$ & $<0.01$ & $<0.001$ & $<0.01$ & $<0.001$ & $<0.001$ & $<0.001$ & $<0.001$ \\
\hline
\end{tabular}

Values in each column with the same letter are not significantly $(p=0.05)$ different between the treatments.

Table 3

Mean \pm standard deviation (sample number) of soil properties

\begin{tabular}{|c|c|c|c|c|}
\hline Treatments & Total porosity (\%) & $\mathrm{BD}\left(\mathrm{g} / \mathrm{cm}^{3}\right)$ & SWC (\%) & Steady $\mathrm{Ks}(\mathrm{mm} / \mathrm{min})$ \\
\hline Control & $47.33 \pm 3.98 b(4)$ & $1.40 \pm 0.10 \mathrm{a}(4)$ & $6.18 \pm 0.83(4)$ & $0.27 \pm 0.50 \mathrm{c}(13)$ \\
\hline A. gmelinii & $57.01 \pm 3.49 \mathrm{a}(7)$ & $1.14 \pm 0.09 b(7)$ & $7.59 \pm 0.45(7)$ & $0.80 \pm 0.07 b(10)$ \\
\hline A. potaninii & $46.98 \pm 6.2 b(6)$ & $1.40 \pm 0.16 a(6)$ & $6.85 \pm 0.86(6)$ & $1.14 \pm 0.08 \mathrm{a}(8)$ \\
\hline P. chrysantha & $53.33 \pm 3.56 a b(5)$ & $1.24 \pm 0.09 \mathrm{ab}(5)$ & $8.42 \pm 2.19(5)$ & $1.15 \pm 0.89 a(9)$ \\
\hline$F$ & 6.941 & 7.168 & 2.999 & 294.273 \\
\hline$p$ & 0.003 & 0.002 & 0.058 & $<0.001$ \\
\hline
\end{tabular}

Note: Bd, bulk density; SWC, soil water content. Values in each column with the same letter are not significantly ( $p=0.05$ ) different between the treatments.

potaninii $>$ Control. Compared to the bare surface, the plant species had $22.8,10.8$ and $36.2 \%$ higher soil water content $(A$. gmelinii, A. potaninii and $P$. chrysantha, respectively). The curves of Ks (infiltration rate) versus time are shown in Fig. 3. All four treatments had similar trends starting with high values and then decreasing to a relatively steady state over time. The decreasing trends could be fitted by logarithm curves (Fig. 3). The time to approach steady state for Control was the earliest, and it took about 36 min. However, it took $42 \mathrm{~min}$ (A. gmelinii), $46 \mathrm{~min}(A$. potaninii) and $44 \mathrm{~min}(P$. chrysantha) for the three plant species. The steady infiltration rates were $0.80 \pm 0.07$ for $A$. gmelinii, $1.14 \pm 0.08$ for $A$. potaninii, and $1.15 \pm 0.89 \mathrm{~mm} / \mathrm{min}$, which were $2.0,3.2$, and 3.3 times higher than the Control $(0.27 \pm 0.50 \mathrm{~mm} /$ min), respectively. They were significantly different among the four treatments $(p<0.001)$ (Table 3$)$.

\subsection{Water runoff and soil loss for different treatments}

For the three species, runoff depth linearly decreased with increasing plants cover (Fig. 4a). The fitted equations of the three plants could account for above $75 \%$ of the variations. The slope gradient of the three fitted lines was $0.026,0.029$, and 0.024 for $A$. gmelinii, $A$. potaninii, and $P$. chrysantha, respectively. It indicated that $A$. potaninii would reduce the most runoff with the equal increase in cover, followed by $A$. gmelinii and $P$. chrysantha, respectively. In addition, the line of $A$. gmelinii was at lower
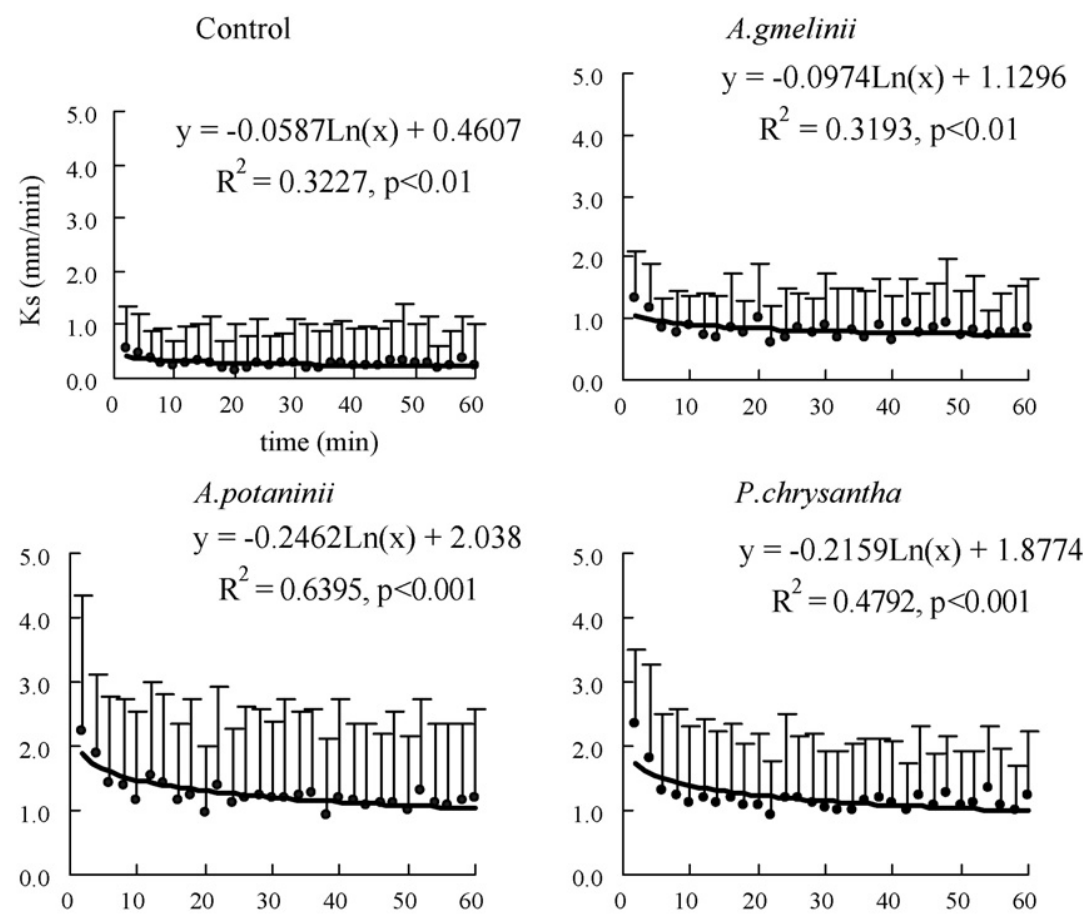

Fig. 3. Infiltration rate change (mean + one standard deviation) over time for Control, A. gmelinii, A. potaninii and P. chrysantha, respectively. 

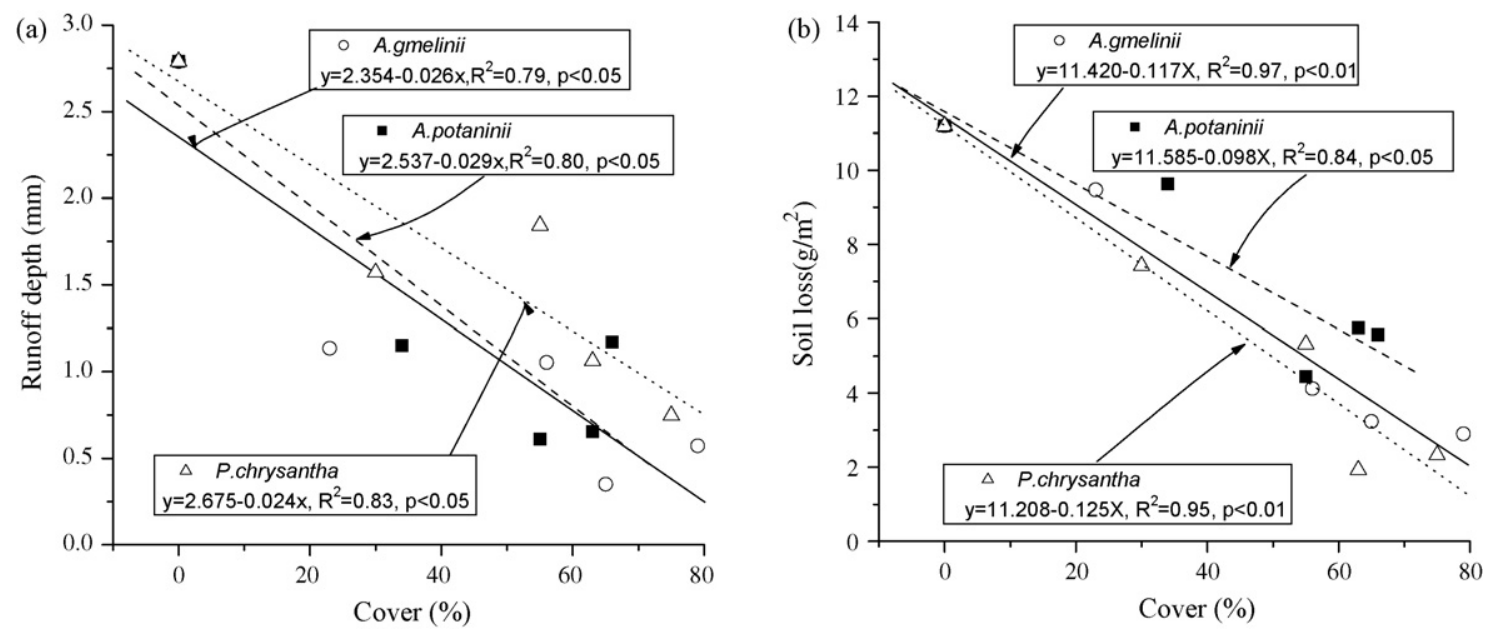

Fig. 4. Plant cover in relation to (a) runoff depth and (b) soil loss.

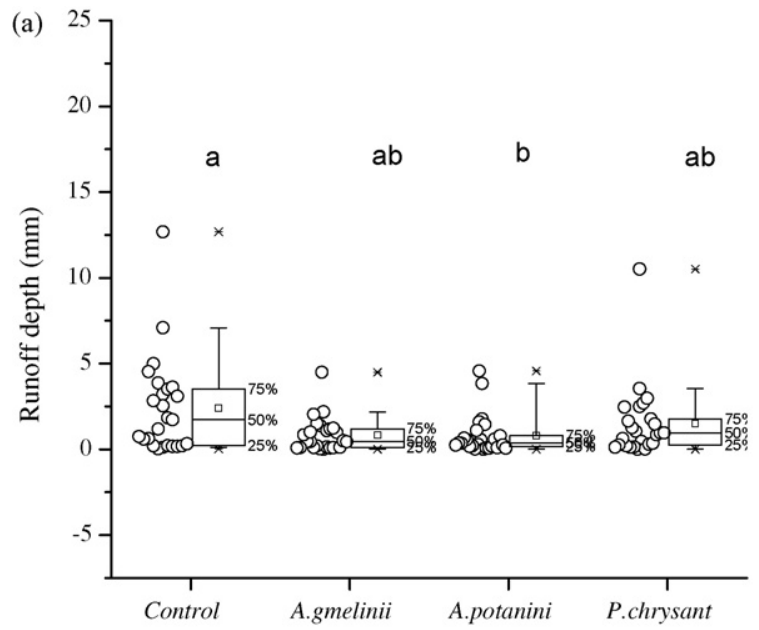

Treatments

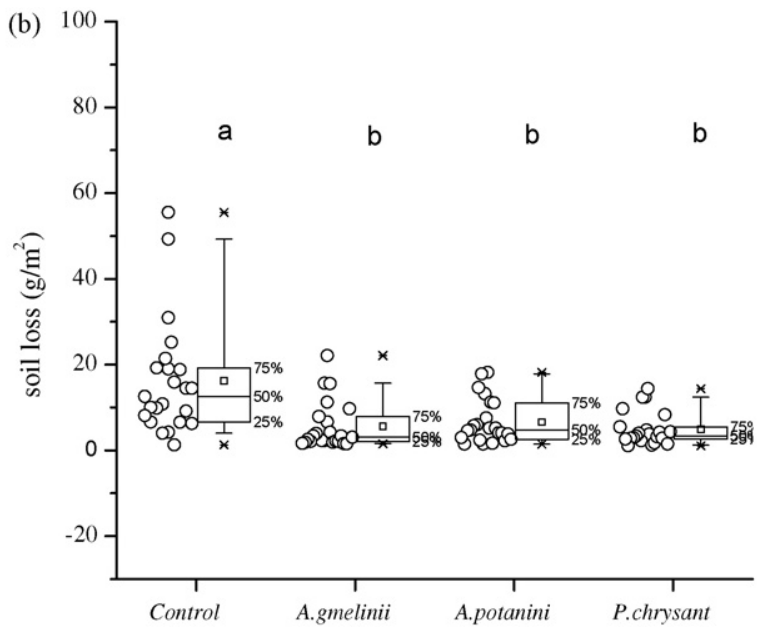

Treatments

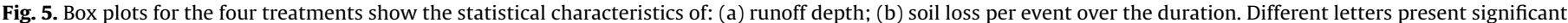
$(p<0.05)$ difference between the treatments.
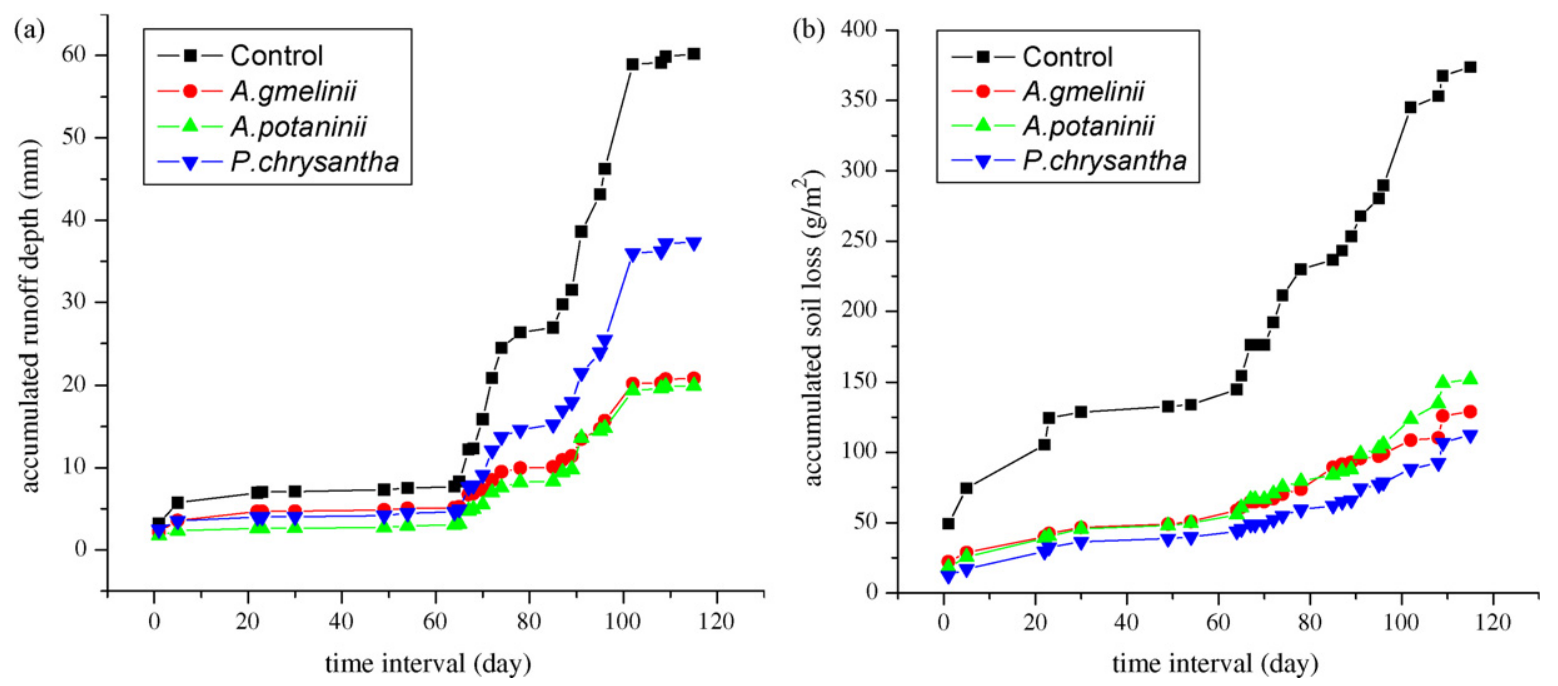

Fig. 6. Accumulated values of the four treatments from 3 July to 25 October 2006: (a) runoff depth; (b) soil loss. 

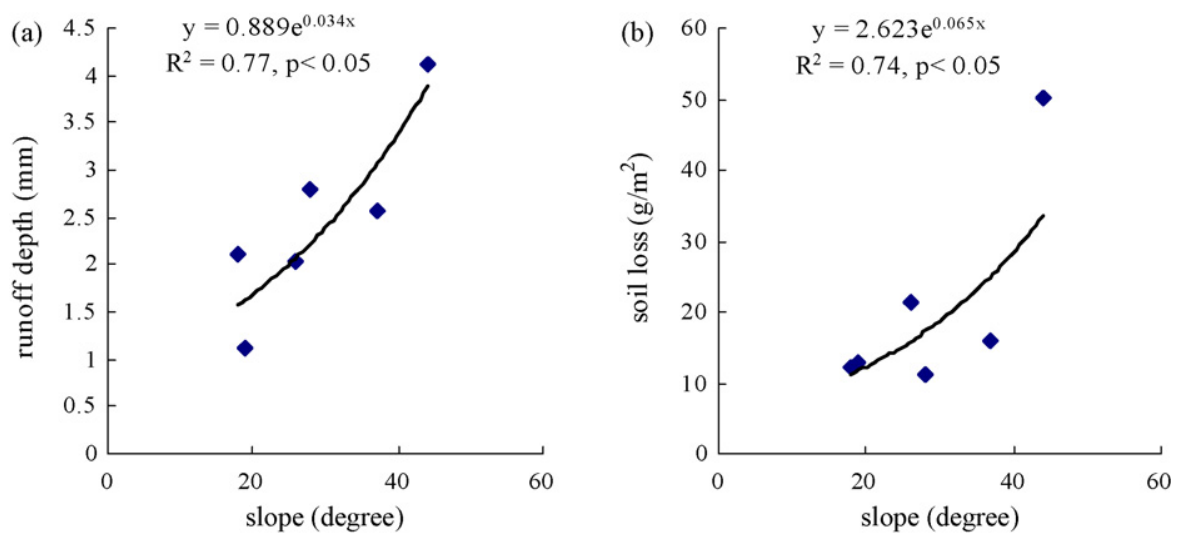

Fig. 7. Slope gradient in relation to (a) runoff depth and (b) soil loss.

position than the other two species when plants cover less than $60 \%$. It means that $A$. gmelinii would produce the least runoff depth at the same cover among the three species when plants cover less than $60 \%$, and followed by $A$. potaninii and $P$. chrysantha having the highest runoff depth. Soil loss also linearly decreased over plant cover (Fig. 4b). The fitted equations could account for 97, 84, and 95\% of variations for A. gmelinii, A. potaninii, and P. chrysantha, respectively. In terms of the slope gradients of the fitted lines, with equal increase in cover, it would decrease the highest soil loss for $P$. chrysantha, followed by $A$. gmelinii and $A$. potaninii, respectively. Likewise, the line of $P$. chrysantha was at the lowest position, which also showed that $P$. chrysantha could produce the least soil loss at the same cover among the three species, and followed by $A$. gmelinii and $A$. potaninii having the highest soil loss, respectively. All dataset of runoff depth and soil loss per event from 3 July to 25 October 2006 for the four treatments are shown in Figs. 5a and b. Only A. potaninii had statistically significant lower runoff depth than Control $(p<0.05)$. The runoff depth value of $P$. chrysantha was slightly higher than the other two plant species (Fig. 5a). Compared to Control (2.41 mm per event), A. gmelinii, A. potaninii and $P$. chrysantha reduced runoff production by $64.9,66.6$ and $38.0 \%$. Control produced significantly more soil loss than the three plant species, and its range of soil loss values was the highest among the four treatments (Fig. 5b). Soil loss for A. potaninii was relatively higher than those for the other species. Comparing with bare surface $\left(16.25 \mathrm{~g} / \mathrm{m}^{2}\right.$ per event), it reduced soil loss by $65.5 \%$ for $A$. gmelinii, $59.3 \%$ for $A$. potaninii, and $69.9 \%$ for $P$. chrysantha, respectively. In terms of the accumulated runoff depth (Fig. 6a), it was always highest for Control, whereas lowest for A. potaninii. Two stages were presented in Fig. 6a, before and after the 64 days point (4 September 2006). The accumulated lines were steady at the first stage, while steep at the second one. As for soil loss, the values of Control were always the highest, while the lowest for $P$. chrysantha (Fig. 6b).

\subsection{Water runoff and soil loss in relation to slope gradient}

Runoff depth and soil loss showed positive exponential relationships to slope gradient (Fig. 7). The slope gradient alone could explain above $70 \%$ of the variance for runoff depth and soil loss.

\section{Discussion}

In arid environments, water resource is the key factor for vegetation restoration. It is necessary to find the species with strong resistance to drought stress and strong capacity in controlling water runoff and soil loss in terms of their morphological and physiological characteristics such as canopy extent, leaf area, specific leaf area and relative leaf water content. The less the specific leaf area and the higher the leaf relative water content, the more adaptive the plant species is in arid environments. In this study, A. gmelinii and A. potaninii are relatively more adaptive to drought stresses (Table 2 ). Two aspects promote the capacity of vegetation in controlling water runoff and soil loss. On the one hand, vegetation could improve soil texture and hydrologic properties by root growth activity and adding litter; on the other hand, canopy cover intercepts rainfall and litter decrease runoff energy (Xu et al., 2006a). In Horqin Sand Land, Mongolia, Zhao et al. (2007) found lower soil bulk density and higher soil water content beneath shrubs than adjacent bare surfaces, and also indicated different species had effects on soil properties to different degrees. Similar to their results, we also found plant-covered surfaces had lower soil bulk density, and higher soil porosity, soil water content and infiltration capacity than bare surfaces (Table 3 and Fig. 3), and the two herbs, A. gmelinii and $P$. chrysantha could improve soil physical properties more efficiently than the small shrub, $A$. potaninii. This might be the dead leaves and branches of the two herbs easily fall off and onto the ground, and thereby increase the litter and organic matter and improve soil texture for the soil matrix. Plant-covered surfaces also had lower runoff and soil loss production than bare surfaces did (Figs. 5 and 6). Similar to the study by Bochet et al. (2006), this study also found that different species had varied effectiveness (Figs. 4-6). Just as $P$. chrysantha relative to $A$. potaninii, it had greater leaf area (Table 2 ), and the dead leaves and branches of $P$. chrysantha easily fall off the plants and onto the ground, which would increase litter cover and improve soil hydrologic properties (Table 3), and thereby decrease runoff energy leading to the high effectiveness in reducing soil loss (Fig. 6b). In addition, we found the accumulated runoff depth values were lower for $P$. chrysantha than $A$. gmelinii at the first stage (July and August), while higher at the second one (September and October, see Fig. 6a) leading to the lower overall effectiveness of $P$. chrysantha in controlling runoff (Fig. 5a), while the accumulated soil loss of $P$. chrysantha didn't sharply increase beyond other species as its accumulated runoff did at the second stage (Fig. 6b). After 4 September (the 64 days point), much more dead leaves and branches of $P$. chrysantha began to fall off the plants so that the canopy cover couldn't effectively intercept rainfall as much as it could before. The fallen leaves and branches could reduce the rainfall energy, which would produce splash erosion otherwise. That is, although more rainfall went into runoff collector, it couldn't detach and take much more sediment. 
By field survey in this study area, Ma et al. (2004a) documented soil water content was negatively associated with slope gradient. This study showed water runoff and soil loss increased with increasing slope gradient (Fig. 7). Thus lowering slope would improve the soil ability of conserving and utilizing rainfall and runoff. We could also take some engineering measures such as building terraces and other measures referenced to $\mathrm{Li}$ et al. (2006d).

Differences in soil environments, and water runoff and soil loss production capacity for bare and plant-covered surfaces increased the heterogeneity of sources and sinks of soil material and runoff water (Imeson and Prinsen, 2004; Puigdefabregas, 2005). These heterogeneous patterns are very important in controlling water runoff and soil loss (Rey, 2004), and some research (Valentin et al., 1999; Martínez Raya et al., 2006) documented the banded or stripped pattern of vegetation would reduce much more water runoff and increase productivity. Thus we should pay attention on the vegetation pattern design for vegetation restoration (Ma et al., 2004b; Li et al., 2006c).

\section{Conclusions}

In this study, we investigated the effects of three plant species with different plant morphologies on water runoff and soil loss under natural conditions. The two herbs, $A$. gmelinii and $P$. chrysantha, have relatively greater effects on soil physical properties (higher soil water content and soil porosity and infiltration capacity, and lower soil bulk density) and higher effectiveness in reducing soil loss. However, $A$. gmelinii has relatively stronger resistance to drought stress and more stable effectiveness in reducing runoff than $P$. chrysantha. Although the small shrub, $A$. potaninii, is more resistant to drought stress, the effectiveness in controlling soil loss is relatively low because of its sparse canopy. Thus the characteristics such as relatively small leaf area but low height and dense canopy might be one criterion for selecting species. In arid environments, it is very difficult to naturally restore vegetation, and human should do some efforts to accelerate the restoration processes especially by focusing on selecting species those are drought-tolerant, and can effectively control water runoff and soil loss, as well as on designing effective vegetation restoration pattern.

\section{Acknowledgements}

This study was supported by the National Natural Science Foundation of China (Nos. 40571005 and 40321101) to Bo-Jie Fu, and by the Project of Chinese Academy of Sciences (No. KZCX2XB2-02-31) to Ke-Ming Ma. We thank Hui Yin, Liang Ge, Xiao-Peng Zheng from Beijing Forestry University for their help in field investigation. We thank two anonymous reviewers for their valuable comments on the earlier versions of the manuscript. We acknowledge Maoxian Mountain Ecosystem Research Station, Chengdu Institute of Biology, CAS for their supports in laboratory facilities.

\section{References}

Bergkamp, G., 1998. A hierarchical view of the interactions of runoff and infiltration with vegetation and microtopography in semiarid shrublands. Catena 33, 201220.

Bochet, E., Poesen, J., Rubio, J.L., 2006. Runoff and soil loss under individual plants of a semi-arid Mediterranean shrubland: influence of plant morphology and rainfall intensity. Earth Surface Processes and Landforms 31, 536-549.

Bochet, E., Rubio, J.L., Poesen, J., 1998. Relative efficiency of three representative matorral species in reducing water erosion at the microscale in a semi-arid climate (Valencia, Spain). Geomorphology 23, 139-150.
Boix-Fayos, C., Martinez-Mena, M., Arnau-Rosalen, E., Calvo-Cases, A., Castillo, V., Albaladejo, J., 2006a. Measuring soil erosion by field plots: understanding the sources of variation. Earth-Science Reviews 78, 267-285.

Boix-Fayos, C., Martinez-Mena, M., Calvo-Cases, A., Arnau-Rosalen, E., Albaladejo, J., Castillo, V., 2008. Causes and underlying processes of measurement variability in field erosion plots in Mediterranean conditions. Earth Surface Processes and Landforms 32, 85-101.

Casermeiro, M.A., Molina, J.A., de la Cruz Caravaca, M.T., Hernando Costa, J., et al., 2004. Influence of scrubs on runoff and sediment loss in soils of Mediterranean climate. Catena 57, 91-107.

Cerda, A., 1998. The influence of geomorphological position and vegetation cover on the erosional and hydrological processes on a Mediterranean hillslope. Hydrological Processes 12, 661-671.

De Baets, S., Poesen, J., Knapen, A., Barbera, G.G., Navarro, J.A., 2007. Root characteristics of representative Mediterranean plant species and their erosionreducing potential during concentrated runoff. Plant and Soil 294, 169-183.

Durán Zuazo, V.H., 2004. Impact of vegetation cover on runoff and soil erosion at hillslope scale in Lanjaron, Spain. The Envionmentalist 24, 39-48.

Hidalgo, G.J.C., Raventos, J., Echevarria, M.T., 1997. Comparison of sediment ratio curves for plants with different architectures. Catena 29, 333-340.

Imeson, A.C., Prinsen, H.A.M., 2004. Vegetation patterns as biological indicators for identifying runoff and sediment source and sink areas for semi-arid landscapes in Spain. Agriculture Ecosystems \& Environment 104, 333-340.

Institute of Soil Science Chinese Academy of Sciences (CAS), 1978. Soil Physical and Chemical Analysis. Shanghai Science Technology Press, Shanghai of China, pp. 524-525.

Li, A., Wang, A., Liang, S., Zhou, W., 2006a. Eco-environmental vulnerability evaluation in mountainous region using remote sensing and GIS-a case study in the upper reaches of Minjiang River, China. Ecological Modeling 192, 175-187.

Li, F., Bao, W., Liu, J., 2005. Leaf characteristics and their relationship of Cotinus coggygria in arid river valley located in the upper reaches of Minjiang River with environmental factors depending on its altitude gradients. Acta Botanica Borealis Occidente Sinica 25 (11), 2277-2284 (in Chinese).

Li, F., Bao, W., Liu, J., Wu, N., 2006b. Eco-anatomical characteristics of Sophoral davidii Leaves along an elevation gradient in upper Minjiang River dry valley. Chinese Journal of Applied Ecology 17 (1), 5-10 (in Chinese).

Li, G., Ma, K., Fu, B., Liu, S., 2006c. Designing regional pattern for ecosystem restoration: a case study. Science in China, Series E: Technological Sciences 49 (Suppl. I), 86-97.

Li, X.Y., Shi, P.J., Sun, Y.L., Tang, J., Yang, Z.P., 2006d. Influence of various in situ rainwater harvesting methods on soil moisture and growth of Tamarix ramosissima in the semiarid loess region of China. Forest Ecology and Management 233, 143-148.

Li, Y.Y., Shao, M.A., 2006. Change of soil physical properties under long-term natural vegetation restoration in the Loess Plateau of China. Journal of Arid Environments 64, 77-96.

Lu, X.X., Ashmore, P., Wang, J., 2003. Sediment yield mapping in a large river basin: the Upper Yangtze, China. Environmental Modelling \& Software 18, 339-353.

Ludwig, J.A., Wilcox, B.P., Breshears, D.D., Tongway, D.J., Imeson, A.C., 2005. Vegetation patches and runoff-erosion as interacting ecohydrological processes in semiarid landscapes. Ecology 86 (2), 288-297.

Ma, K.M., Fu, B.J., Liu, S.L., Guan, W.B., Liu, G.H., Lv, Y.H., Anand, M., 2004a. Multiplescale soil moisture distribution and its implications for ecosystem restoration in an arid river valley, China. Land Degradation and Development 15, 75-85.

Ma, K.M., Fu, B.J., Li, X.Y., Guan, W.B., 2004b. The regional pattern for ecological security (RPES): concepts and theoretical bases. Acta Ecologica Sinica 24 (4), 762-768 (in Chinese).

Martínez Raya, A., Durán-Zuazo, V.H., Francia-Martínez, J.R., 2006. Soil erosion and runoff response to plant-cover strips on semiarid slopes (SE Spain). Land Degradation and Development 17 (1), 1-11.

Martinez-Mena, M., Alvarez-Rogel, J., Albaladejo, J., Castillo, V.M., 1999. Influence of vegetal cover on sediment particle size distribution in natural rainfall conditions in a semiarid environment. Catena 38, 175-190.

Puigdefabregas, J., 2005. The role of vegetation patterns in structuring runoff and sediment fluxes in drylands. Earth Surface Processes and Landforms 30, 133-147.

Rey, F., 2004. Effectiveness of vegetation barriers for marly sediment trapping. Earth Surface Processes and Landforms 29, 1161-1169.

Sanchez, L.A., Ataroff, M., Lopez, R., 2002. Soil erosion under different vegetation covers in the Venezuelan Andes. The Environmentalist 22, 161-172.

Valentin, C., d'Herbes, J.M., Poesen, J., 1999. Soil and water components of banded vegetation patterns. Catena 37, 1-24.

Xu, X., Ma, K., Fu, B., Liu, X., Huang, Y., Qi, J., 2006a. Research review of the relationship between vegetation and soil loss. Acta Ecologica Sinica 26 (9), 3137-3143.

Xu, X., Zhang, K., Kong, Y., Chen, J., Yu, B., 2006b. Effectiveness of erosion control measures along the Qinghai-Tibet plateau highway, Tibetan plateau, China. Transportation Research, Part D: Transport and Environment 11, 302-309.

Yan, H., Bi, H., Li, R., Eldridge, R., Wu, Z., Li, Y., Simpson, J., 2006. Assessing climatic suitability of Pinus radiata (D. Don) for summer rainfall environment of southwest China. Forest Ecology and Management. 234, 199-208.

Zhao, H.L., Zhou, R.L., Su, Y.Z., Zhang, H., Zhao, L.Y., Drake, S., 2007. Shrub facilitation of desert land restoration in the Horqin Sand Land of Inner Mongolia. Ecological Engineering 31, 1-8.

Zhu, P.F., Li, D.R., 1989. Forest soil in Sichuan. Sichuan Science and Technology Press, Chengdu (in Chinese). 